\title{
Papers
}

\section{Systematic review of efficacy of cognitive behaviour therapies in childhood and adolescent depressive disorder}

\author{
Richard Harrington, Jane Whittaker, Philip Shoebridge, Fiona Campbell
}

\begin{abstract}
Objective: To determine whether cognitive behaviour therapy is an effective treatment for childhood and adolescent depressive disorder.

Design: Systematic review of six randomised trials comparing the efficacy of cognitive behaviour therapy with inactive interventions in subjects aged 8 to 19 years with depressive disorder.

Main outcome measure: Remission from depressive disorder.

Results: The rate of remission from depressive disorder was higher in the therapy group $(129 / 208$; $62 \%)$ than in the comparison group $(61 / 168 ; 36 \%)$. The pooled odds ratio was $3.2(95 \%$ confidence interval 1.9 to 5.2), suggesting a significant benefit of active treatment. Most studies, however, were based on relatively mild cases of depression and were of only moderate quality.

Conclusions: Cognitive behaviour therapy may be of benefit for depressive disorder of moderate severity in children and adolescents. It cannot, however, yet be recommended for severe depression. Definitive large trials will be required to determine whether the results of this systematic review are reliable.
\end{abstract}

\section{Introduction}

Depressive disorders are a common problem in child psychiatric clinics. ${ }^{1}$ These common disorders are associated with a range of adverse outcomes, including severe social impairment, long term effects on cognitive development, suicidal behaviour, and a high risk of recurrence. ${ }^{2}$ There is much literature reviewing the usefulness of tricyclic medication in childhood depression, but a systematic review found tricyclics to be of uncertain benefit. ${ }^{3}$ The results of randomised studies of selective serotonin reuptake inhibitors have been contradictory, with one positive ${ }^{4}$ and one negative result. $^{5}$

There has therefore been a growing interest in psychological treatments, particularly in cognitive behaviour therapy. The results of trials of cognitive behaviour therapy in depressed young people have, however, been difficult to interpret. Although some trials have found significant benefits, the numbers have been small and the confidence intervals for the rate of improvement have been wide. In addition, the quality of the studies varied greatly. We therefore submitted
Features of cognitive behaviour therapy with depressed children and adolescents

- Eight to 12 weekly sessions

- Therapist and child collaborate to solve problems

- Emphasis on dealing with current difficulties

- Structured approach, with intervention based on case formulation and the child's development stage

- Treatment includes cognitive (for example, challenging negative styles of thinking) and behavioural (for example, advice about poor sleep) elements

the existing literature to a systematic review. We pooled the results of randomised trials to see whether cognitive behaviour therapy is superior to other conditions in the treatment of childhood and adolescent depressive disorders. We also examined whether the results were materially influenced by the quality of the reported studies.

\section{Methods}

Definitions and inclusion criteria

The systematic review was restricted to studies in which one of the therapies was a recognised form of cognitive behaviour therapy as described in standard textbooks on the subject. ${ }^{67}$ Studies of family therapy ${ }^{89}$ or interpersonal psychotherapy ${ }^{10}$ were excluded.

It is important to minimise clinical heterogeneity in systematic reviews, ${ }^{11}$ and most authorities agree that in young people depressive disorder should be distinguished from depressive symptoms. ${ }^{12}{ }^{13}$ Studies were therefore included in the systematic review only if they described subjects diagnosed with depressive disorder by using standardised criteria. ${ }^{14}$ The other inclusion criteria were that patients were aged between 6 and 18 years and were randomly allocated to cognitive behaviour therapy or a comparison intervention.

\section{Search methods}

The search was conducted in stages. In the first stage, conducted by $\mathrm{RH}$, the literature was searched with Medline (1966-97) and Psych-lit. Reference lists from reviews and book chapters were searched, and conference proceedings were reviewed. This stage suggested that there were probably enough studies suitable for

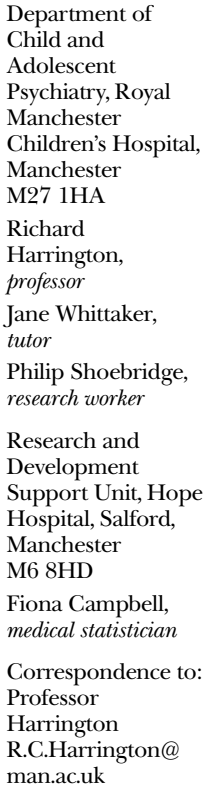

BMJ 1998;316:1559-63 
inclusion in a quantitative analysis. ${ }^{15}$ In the second stage, conducted independently by JW and PS, the computer searches were repeated and all journals that had published a randomised controlled trial in this field were searched manually. When relevant, authors of published papers were approached for further details of their work. Investigators working in the specialty were contacted. The Cochrane library was also searched for randomised trials.

\section{Search results}

The search identified 22 potential comparative studies in which cognitive behaviour therapies had been used with depressed young people. Four studies were excluded because assignment to treatment was not random, ${ }^{16-19}$ one because it was an interim analysis of an ongoing study, ${ }^{20}$ and 11 because they involved children with depressive symptoms and not depressive disorder. ${ }^{21-31}$ This left six randomised trials of cognitive behaviour therapy for depressive disorder in young people. ${ }^{32-37}$ Two of the trials were conducted by the same research group ${ }^{32}{ }^{34}$ but it was clear from the trial descriptions that they were based on different samples. We did not find any studies that compared cognitive behaviour therapy with medication.

\section{Quality assessment}

Quality of the studies was assessed by using a modified version of the scheme used by Hazell and coworkers in their systematic review of the tricyclic studies. ${ }^{3}$ Their scheme was based on the method of Chalmers and colleagues. ${ }^{38}$ The cognitive behaviour therapy studies were rated independently by JW and PS and disagreements were resolved by consensus. Each of 12 features of a study was rated on a $0-3$ scale, making a total possible score of 36 . These features were:

- Quality of description of randomisation

- Inclusion of data on subjects who subsequently withdrew from the study (intention to treat)

- Degree to which the assessors were blind to the allocated treatment

- Degree to which the expectancy of subjects about treatment was assessed

- Clarity of description of improvement
- Use of multiple informants to assess outcome

- Whether the therapy was specified in a manual and the degree to which the adherence of therapists to the manual was checked

- Degree to which compliance with the therapy was assessed

- Whether concurrent treatment was held constant

- Length of baseline assessment

- Control for previous treatment

- Control for comorbidity

To confirm that we were using the quality rating in the same way as Hazell et al, the tricyclic studies were rated again by JW and PS. Their consensus ratings strongly correlated with those of Hazell et al $(r=0.92)$.

\section{Outcome measurement}

In all studies depressive disorder was diagnosed with operational criteria. ${ }^{14}$ Five of the six studies used the same standardised interview to establish whether these criteria were met (Puig-Antich J, Chambers W, Schedule for affective disorders and schizophrenia for school aged children, available from New York State Psychiatric Institute). In the sixth the clinician made a global judgment on the basis of an interview and the subject's responses on standardised depression questionnaires. ${ }^{33}$ Only two studies have thus far reported follow up data, ${ }^{35}$ and this meta-analysis was therefore restricted to outcomes immediately after treatment. The outcome was remission from depressive disorder.

\section{Statistical analysis}

For each study we estimated the ratio of the odds of remission after cognitive behaviour therapy compared with the odds in the comparison group or groups. Confidence intervals were calculated with the Logit approximation. The pooled odds ratio was estimated with the DerSimonian Laird method, ${ }^{40}$ with a random effects model. A test of heterogeneity was performed.

\section{Results}

Table 1 summarises descriptive information on the studies. No study included inpatients. Cognitive behaviour therapy was compared with a heterogeneous

Table 1 Randomised outcome studies of cognitive behavioural interventions in childhood and adolescent depressive disorder

\begin{tabular}{|c|c|c|c|c|c|c|c|c|}
\hline Reference & $\begin{array}{c}\text { Age } \\
\text { (years) }\end{array}$ & $\begin{array}{l}\text { Type of cognitive behavioural } \\
\text { therapy }\end{array}$ & $\begin{array}{c}\text { No randomised } \\
\text { to cognitive } \\
\text { behavioural } \\
\text { therapy }\end{array}$ & Comparison condition/s & $\begin{array}{l}\text { No randomised } \\
\text { to comparison }\end{array}$ & Outcome measure & Sample & $\begin{array}{l}\text { Quality } \\
\text { score }\end{array}$ \\
\hline \multirow[t]{2}{*}{ Lewinsohn et al, $1990^{32}$} & $14-18$ & CWDC, subject & 24 & Waiting list & 24 & KSADS & $\begin{array}{l}\text { Advertisements and } \\
\text { clinics }\end{array}$ & 20 \\
\hline & & CWDC, subject and parent & 21 & & & & & \\
\hline Reed, $1994^{33}$ & $14-19$ & Structured learning therapy & 12 & Art exercises & 6 & Global judgment* & Community & 15 \\
\hline Vostanis et al, $1996^{36}$ & $8-17$ & $\begin{array}{l}\text { Depression treatment } \\
\text { programme }\end{array}$ & 29 & Attention placebo & 28 & KSADS & Outpatient clinics & 23 \\
\hline Wood et al, $1996^{35}$ & $9-17$ & $\begin{array}{l}\text { Depression treatment } \\
\text { programme }\end{array}$ & 26 & Relaxation training & 27 & KSADS & Outpatient clinics & 32 \\
\hline \multirow[t]{2}{*}{ Brent et al, $1997^{37}$} & $13-18$ & Adapted from Beck & 37 & Supportive therapy & 35 & KSADS & $\begin{array}{l}\text { Outpatient clinics and } \\
\text { advertisements }\end{array}$ & 25 \\
\hline & & & & Family therapy & 35 & & & \\
\hline \multirow[t]{2}{*}{ Lewinsohn et al, $1997^{34} \dagger$} & $13-18$ & CWDC, subject & 37 & Waiting list & 27 & KSADS & Community & 21 \\
\hline & & CWDC, subject and parent & 32 & & & & & \\
\hline
\end{tabular}

CWDC=Coping with depression course.

KSADS=Schedule for affective disorders and schizophrenia—child.

*Global rating of improvement by clinician based on scores on children's depression inventory, Beck, and other inventories.

†Final report not yet available therefore numbers randomised and quality rating were based on information available in reports published so far. 
Table 2 Results for subjects who were followed up, expressed as numbers without depressive disorder in each group at end of treatment

\begin{tabular}{|c|c|c|c|c|c|}
\hline \multirow[b]{2}{*}{ Study } & \multicolumn{2}{|c|}{ Cognitive behaviour therapy } & \multicolumn{2}{|c|}{ Comparison condition } & \multirow[b]{2}{*}{$\begin{array}{l}\text { Odds ratio }(95 \% \\
\text { confidence interval }\end{array}$} \\
\hline & No withdrawn & $\begin{array}{l}\text { No without depressive disorder } \\
\text { after therapy/No treated }\end{array}$ & No withdrawn & $\begin{array}{l}\text { No without depressive disorder } \\
\text { after therapy/No treated }\end{array}$ & \\
\hline Lewinsohn et al,1990 ${ }^{32 *}$ & 5 & $18 / 40$ & 5 & $1 / 19$ & 14.7 (1.9 to 117.5$)$ \\
\hline Reed, $1994^{33}$ & 1 & $6 / 11$ & 0 & $0 / 6$ & $15.4 \dagger(0.7$ to 318.3$)$ \\
\hline Vostanis et al, $1996^{36}$ & 0 & $25 / 29$ & 0 & $21 / 28$ & $2.1(0.5$ to 8.1$)$ \\
\hline Wood et al, $1996^{35}$ & 2 & $13 / 24$ & 3 & $5 / 24$ & $4.5(1.3$ to 16.0$)$ \\
\hline Brent et al, $1997^{37} \ddagger$ & 2 & $21 / 35$ & 6 & $21 / 64$ & $3.1(1.2$ to 7.7$)$ \\
\hline Lewinsohn et al, $1997^{34 *}$ & Not known & $46 / 69$ & Not known & $13 / 27$ & 2.2 (0.8 to 5.6$)$ \\
\hline Pooled results & & $129 / 208(62.0 \%)$ & & $61 / 168(36.3 \%)$ & $3.2(1.9$ to 5.2$)$ \\
\hline
\end{tabular}

${ }^{*}$ Two cognitive behavioural therapy groups collapsed into one cell.

†Haldane approximation.

$\ddagger$ Two comparison interventions collapsed into one cell.

set of comparison interventions. Most of these interventions were designed either to be inactive (such as waiting list) or to be an attention placebo (for example, relaxation training, art exercises).

\section{Per protocol analysis}

Table 2 shows the numbers without depressive disorder at the end of treatment. All studies showed positive effects in favour of cognitive behaviour therapy. In three studies the $95 \%$ confidence intervals for the odds ratio did not include 1 (figure), indicating a significant difference in favour of cognitive behaviour therapy over the comparison conditions $(129 / 208 v$ $61 / 168)$. There was no significant heterogeneity across the sample $\left(\chi^{2}=4.5 ; \mathrm{df}=5 ; \mathrm{P}=0.47\right)$. The pooled odds ratio was 3.2 (95\% confidence interval 1.9 to 5.2$)$, suggesting significant improvement in the cognitive behaviour therapy group over the comparison group.

The high rate of improvement in the comparison group $(36 \%)$ meant, however, that for every 100 patients who were treated with cognitive behaviour therapy there were just 26 extra patients $(62-36)$ who improved because of it. Four patients (95\% confidence interval 3 to 6 patients) would therefore need to be treated with cognitive behaviour therapy to gain one additional remission above that arising from the comparison interventions.

\section{Intention to treat analysis}

The per protocol analysis ignored withdrawals from treatment (table 2) and may therefore have exaggerated the effects of cognitive behaviour therapy. To obtain a more conservative estimate of the effect of implementing therapy we conducted an intention to

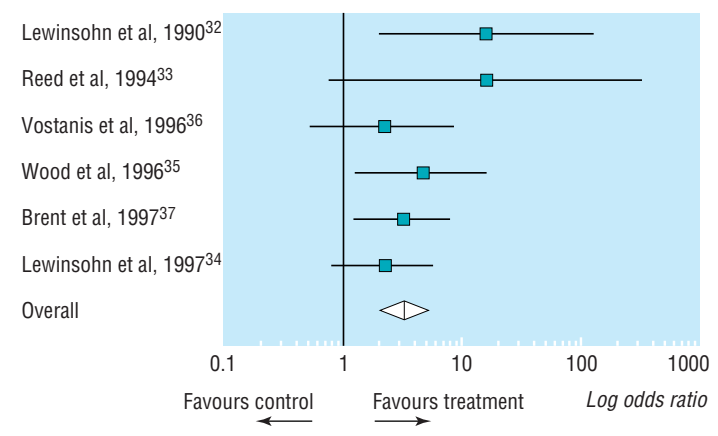

Efficacy of cognitive behavioural therapy in childhood and adolescent depressive disorder. Cochrane odds ratio plot (random effects model) treat analysis in which we assumed that all withdrawals in the cognitive behaviour therapy group did not remit and all withdrawals in the control groups remitted (that is, remission rates of $129 / 218$ and $75 / 182$, respectively). The pooled odds ratio was 2.2 (1.4 to 3.5$)$.

\section{Study quality}

The mean quality rating of the cognitive behaviour therapy studies was 22.7. This is similar to that in the tricyclic studies, ${ }^{3}$ in which the mean for the five studies that presented data on remission was 23.8. There was a small negative association between the quality rating and the odds ratio (rank $r=-0.46 ; \mathrm{P}>0.10$ ). This was largely because the two trials with lower scores on the quality scale showed the strongest treatment effects (tables 1 and 2). The effect of cognitive behaviour therapy was still found to be significant when these trials were excluded, with remission rates in an intention to treat analysis of $105 / 161$ in the cognitive behaviour therapy group and 69/152 in the comparison conditions. This gave an odds ratio of 2.2 (1.3 to 3.5$)$.

\section{Discussion}

The treatment of depressive disorders is an important clinical issue for child mental health teams yet little is known about the best ways of helping these children. A systematic review of the tricyclic studies suggested that tricyclics were of uncertain benefit. ${ }^{3}$ The present systematic review of cognitive behaviour therapy studies seems to show that it is a useful treatment for children and adolescents with depressive disorders. Several issues need to be borne in mind, however, in the interpretation of these results.

\section{Potential biases}

With only six small trials it is difficult to use techniques such as funnel plots to examine the possibility of bias. Nevertheless, the absence of studies with a negative odds ratio does raise this possibility because it would be expected that even when a treatment is effective some small trials would have negative results. ${ }^{41}$

Any systematic review can be biased by the selective publication of positive results or by the delayed publication of negative findings. At present there is no reliable method for excluding such publication biases. We did, however, make efforts to ascertain unpublished work, and indeed two of the six studies included here were unpublished at the time of the review. ${ }^{34}$ Bias can 
Key messages

- Depressive disorders are a common problem in child psychiatric clinics, but a recent systematic review found that tricyclic medication was of unproved benefit

- This systematic review identified six randomised trials of a psychological treatment-cognitive behaviour therapy-in subjects aged 8 to 19 years with depressive disorder

- The results seemed to show that cognitive behaviour therapy is an effective treatment for depressive disorder of moderate severity

- Because of the small number of trials available for this quantitative analysis definitive large trials will be required to determine whether the present results are reliable

also occur if there is selective exclusion of subjects after randomisation. Our intention to treat analysis, however, showed that even with the most conservative estimate of the effects of selective withdrawal there was still a significant benefit of cognitive behaviour therapy.

The small negative association between study quality and the odds ratio suggests a possible bias away from negative results in the studies with lower ratings on the quality scale. This association was largely due to two studies and their removal made no material difference to the results. Nevertheless, it has to be said that the quality of the remaining trials was only moderate. Most did not give an adequate description of the randomisation procedures. In only one was an attempt made to measure and adjust for the lack of blindness of outcome assessors that often occurs in studies of psychosocial treatments.

\section{Clinical heterogeneity}

There was no statistical evidence of heterogeneity in this meta-analysis, but power to detect heterogeneity was low because of the small number of available trials. It is likely, however, that there was some clinical heterogeneity. In three of the trials factors that predict outcome were analysed within the studies. These analyses all showed that greater severity of depression was a significant predictor of failure to remit after cognitive behaviour therapy (DA Brent et al, personal communication). ${ }^{42}{ }^{43}$ The implication is that cognitive behaviour therapy may be most effective for depression of moderate severity.

It must also be borne in mind that young people admitted to the cognitive behaviour therapy trials were generally less severely impaired than those admitted to the tricyclic trials. For instance, in the cognitive behaviour therapy study of Wood et al only a quarter of subjects had endogenous depression, ${ }^{35}$ whereas in the tricyclic studies more than half the patients had endogenous features. ${ }^{44-46}$ Moreover, many of the participants in the tricyclic trials were inpatients.

\section{Spontaneous improvement}

The high rate of improvement among children in the comparison group also requires some comment. The comparison group consisted mainly of interventions that were designed either to be inactive or to be an attention placebo. Only one study included an active comparison intervention-family therapy. ${ }^{37}$ The finding that more than a third of depressed patients improved with these inactive interventions suggests that there is a high rate of spontaneous remission in moderately severe juvenile depression. Cognitive behaviour therapy is an expensive intervention, taking up to 16 sessions in some of the studies reviewed here. There is a strong case then for using a brief supportive intervention as the first line treatment and reserving cognitive behaviour therapy for patients who fail to respond.

\section{Conclusions}

This systematic review suggests that cognitive behaviour therapy may be of benefit for mild or moderate depressive disorder in young people. It was based on only six trials, however, many of which were relatively small. Definitive larger trials will therefore be required to establish whether the results of the present meta-analysis are reliable. In the meantime, the available data suggest that cognitive behaviour therapy is a promising treatment for depressed young people.

Contributors: RH had the original idea for the study, conducted the first stage of the literature search, and wrote the paper. JW and PS conducted the second stage of the search and carried out the quality assessments. FC undertook the statistical analysis.

Funding: PS was supported by the MacArthur Foundation Research Network on Psychopathology and Development (1996-7). RH's recent research on the treatment of adolescent depression has been funded by the NHS Executive North West and by the Department of Health.

Conflict of interest: None.

1 Kolvin I, Barrett ML, Bhate SR, Berney TP, Famuyiwa OO, Fundudis T, et al. The Newcastle child depression project: diagnosis and classification of depression. Br J Psychiatry 1991;159 (suppl 11):9-21.

2 Harrington RC. Affective disorders. In: Rutter M, Taylor E, Hersov L, eds. Child and adolescent psychiatry: modern approaches. 3rd ed. Oxford: Blackwell Scientific, 1994:330-50.

3 Hazell P, O'Connell D, Heathcote D, Robertson J, Henry D. Efficacy of tricyclic drugs in treating child and adolescent depression: a meta-analysis BMJ 1995;310:897-901.

4 Emslie G, Rush A, Weinberg W, Kowatch R, Hughes C, Carmody T, et al. A double-blind, randomized placebo-controlled trial of fluoxetine in depressed children and adolescents. Arch Gen Psychiatry 1997;54:1031-7.

5 Simeon JG, Dinicola VF, Ferguson HB, Copping W. Adolescent depression: a placebo-controlled fluoxetine treatment study and follow-up. Prog Neuro-Psychopharm Biol Psychiatry 1990;14:791-5.

6 Hawton K, Salkovskis PM, Kirk J, Clark DM. Cognitive behaviour therapy for psychiatric problems. A practical guide. Oxford: Oxford University Press, 1989.

7 Williams JMG. The psychological treatment of depression. 2nd ed. London: Routledge, 1992.

8 Beardslee WR, Wright E, Rothberg PC, Salt P, Versage E. Response of families to two preventive intervention strategies: long-term differences in behavior and attitude change. $J$ Am Acad Child Adolesc Psychiatry in behavior and

9 Sandler IN, West SG, Baca L, Pillow DR, Gersten JC, Rogosch F, et al. Linking empirically based theory and evaluation: the family bereavement program. Am J Comm Psychol 1992;20:491-521.

10 Mufson L, Moreau D, Weissman MM, Klerman GL. Interpersonal psychotherapy for depressed adolescents. New York: Guilford Press, 1993.

11 Thompson SG. Why sources of heterogeneity in meta-analysis should be investigated. $B M J$ 1994;309:1351-5

12 Goodyer IM. Depression in childhood and adolescence. In: Paykel ES, ed. Handbook of affective disorders. 2nd ed. Edinburgh: Churchill Livingstone, 1992:585-600.

13 Rutter M. The developmental psychopathology of depression: issues and perspectives. In: Rutter M, Izard C, Read P, eds. Depression in young people. Developmental and clinical perspectives. New York: Guilford Press, 1986:3-30.

14 American Psychiatric Association. Diagnostic and statistical manual of mental disorders-DSM-III-R. 3rd ed, rev. Washington: American Psychiatric Association, 1987.

15 Harrington RC, Wood A, Verduyn C. Clinically depressed adolescents. In: Graham P, ed. Cognitive behaviour therapy for children and their families. Cambridge: Cambridge University Press, 1998:163-200.

16 Butler L, Meizitis S, Friedman R, Cole E. The effect of two school-based intervention programs on depressive symptoms in pre-adolescents. Am Educ Res J 1980;17:111-9.

17 Fine S, Forth A, Gilbert M, Haley G. Group therapy for adolescent depressive disorder: a comparison of social skills and therapeutic support. JAm Acad Child Psychiatry 1991;30:79-85.

18 Jaycox LH, Reivich KJ, Gillham J, Seligman MEP. Prevention of depressive symptoms in school children. Behav Res Ther 1994:32:801-16.

9 Kroll L, Harrington RC, Gowers S, Frazer J, Jayson D. Continuation of cognitive-behavioural treatment in adolescent patients who have 
remitted from major depression. Feasibility and comparison with historical controls. J Am Acad Child Adolesc Psychiatry 1996;35:1156-61.

20 Rossello J, Bernal G. Adapting cognitive-behavioral and interpersonal treatments for depressed Puerto Rican adolescents. In: Hibbs E, Jensen PS, eds. Psychosocial treatments for child and adolescent disorders. Empirically based strategies for clinical practice. Washington: American Psychological Association, 1996:157-85.

21 Reynolds WM, Coats KI. A comparison of cognitive-behavioural therapy and relaxation training for the treatment of depression in adolescents. $J$ Consult Clin Psychol 1986;54:653-60.

22 Stark KD, Reynolds WM, Kaslow N. A comparison of the relative efficacy of self-control therapy and a behavioral problem-solving therapy for depression in children. J Abnorm Child Psychol 1987;15:91-113.

23 Liddle B, Spence SH. Cognitive-behaviour therapy with depressed primary school children: a cautionary note. Beh Psychotherapy $1990 \cdot 18 \cdot 85-102$.

24 Kahn JS, Kehle TJ, Jenson WR, Clark E. Comparison of cognitivebehavioral, relaxation, and self-modelling interventions for depression among middle-school students. School Psychol Rev 1990;2:196-211.

25 King CA, Kirschenbaum DS. An experimental evaluation of a school-based program for children at risk: Wisconsin early intervention. $J$ Comm Psychol 1990;18:167-77.

26 Kellam SG, Werthamer-Larsson L, Dolan LJ, Hendricks Brown C, Mayer LS, Rebok GW, et al. Developmental epidemiologically based preventive trials: baseline modeling of early target behaviors and depressive symptoms. Am J Comm Psychol 1991;19:563-84.

27 Marcotte D, Baron P. L'efficacite d'une strategie d'intervention emotivo-rationnelle aupres d'adolescents depressifs du milieu scolaire. Can J Counselling 1993;27:77-92.

28 Clarke GN, Hawkins W, Murphy M, Sheeber L. School-based primary prevention of depressive symptomatology in adolescents. Findings from two studies. J Adolesc Res 1993;8:183-204.

29 Clarke GN, Hawkins W, Murphy M, Sheeber LB, Lewinsohn PM, Seeley JR. Targeted prevention of unipolar depressive disorder in an at-risk sample of high school adolescents: a randomized trial of a group cognitive intervention. J Am Acad Child Adolesc Psychiatry 1995;34:312-21.

30 Stark KD. Childhood depression: school-based intervention. New York: Guilford Press, 1990

31 Weisz JR, Thurber CA, Sweeney L, Proffitt VD, LeGagnoux GL. Brief treatment of mild-to-moderate child depression using primary and secondary control enhancement training. J Consult Clin Psychol 1997;65:703-7.

32 Lewinsohn PM, Clarke GN, Hops H, Andrews J. Cognitive-behavioural treatment for depressed adolescents. Beh Ther 1990;21:385-401.

33 Reed MK. Social skills training to reduce depression in adolescents. Adolescence 1994:29:293-302.
34 Lewinsohn P, Clarke GN, Rowhde P, Hops H, Seeley J. A course in coping: a cognitive-behavioral approach to treatment of adolescent depression. In: Hibbs ED, Jensen PS, eds. Psychosocial treatments for child and adolescent disorders. Washington DC: Americam Psychiatric Association, 1997:109-35.

35 Wood AJ, Harrington RC, Moore A. Controlled trial of a brief cognitivebehavioural intervention in adolescent patients with depressive disorders. J Child Psychol Psychiatry 1996;37:737-46.

36 Vostanis P, Feehan C, Grattan E, Bickerton W. Treatment for children and adolescents with depression: lessons from a controlled trial. Clin Child Psychol Psychiatry 1996;1:199-212.

37 Brent D, Holder D, Kolko D, Birmaher B, Baugher M, Roth C, et al. A clinical psychotherapy trial for adolescent depression comparing cognitive, family, and supportive treatments. Arch Gen Psychiatry 1997;54:877 85.

38 Chalmers TC, Smith H, Blackburn B, Silverman B, Schroeder B, Reitman $\mathrm{D}$, et al. A method for assessing the quality of a randomized control trial. Cont Clin Trials 1981;2:31-49.

39 Vostanis P, Feehan C, Grattan E, Bickerton W. A randomized controlled out-patient trial of cognitive-behavioural treatment for children and adolescents with depression: 9-month follow-up. J Affect Disord 1996;40:105-

40 DerSimonian R, Laird N. Meta-analysis in clinical trials. Cont Clin Trials 1986;7:177-88

41 Egger M, Davey Smith G, Schneider M, Minder C. Bias in meta-analysis detected by a simple graphical test. BMJ 1997;315:629-34.

42 Jayson D, Wood AJ, Kroll L, Frazer J, Harrington RC. Predictors of response to cognitive-behaviour therapy in adolescent depressive disorder. J Am Acad Child Adolesc Psychiatry 1997;37:35-9.

43 Clarke GN, Hops H, Lewinsohn PM, Andrews JA, Seeley JR, Williams JA. Cognitive-behavioral group treatment of adolescent depression: prediction of outcome. Behav Ther 1992;23:341-54.

44 Geller B, Cooper TB, Graham DL, Marsteller FA, Bryant DM. Double-blind placebo-controlled study of nortriptyline in depressed adolescents using a "fixed plasma level" design. Psychopharm Bult 1990;26:85-90.

45 Geller B, Cooper TB, Graham DL, Fetner HH, Marsteller FA, Wells JM. Pharmacokinetically designed double-blind placebo-controlled study of nortriptyline in 6- to 12-year-olds with major depressive disorder. $J \mathrm{Am}$ Acad Child Psychiatry 1992;31:34-44.

46 Puig-Antich J, Perel JM, Lupatkin W, Chambers WJ, Tabrizi MA, King J, et al. Imipramine in prepubertal major depressive disorders. Arch Gen Psychiatry 1987;44:81-9.

(Accepted 13 April 1998)

\title{
Effectiveness of treatments for infantile colic: systematic review
}

\author{
P L B J Lucassen, W J J Assendelft, J W Gubbels, J T M van Eijk, W J van Geldrop, A Knuistingh Neven
}

\begin{abstract}
Objective: To evaluate the effectiveness of diets, drug treatment, and behavioural interventions on infantile colic in trials with crying or the presence of colic as the primary outcome measure.
\end{abstract}

Data sources: Controlled clinical trials identified by a highly sensitive search strategy in Medline (1966-96), Embase (1986-95), and the Cochrane Controlled Trials Register, in combination with reference checking for further relevant publications. Keywords were crying and colic.

Study selection: Two independent assessors selected controlled trials with interventions lasting at least 3 days that included infants younger than 6 months who cried excessively.

Data synthesis: Methodological quality was assessed by two assessors independently with a quality assessment scale (range 0-5). Effect sizes were calculated as percentage success. Effect sizes of trials using identical interventions were pooled using a random effects model.

Results: 27 controlled trials were identified. Elimination of cows' milk protein was effective when substituted by hypoallergenic formula milks (effect size 0.22 (95\% confidence interval 0.09 to 0.34$))$. The effectiveness of substitution by soy formula milks was unclear when only trials of good methodological quality were considered. The benefit of eliminating cows' milk protein was not restricted to highly selected populations. Dicyclomine was effective (effect size 0.46 ( 0.33 to 0.60$)$ ), but serious side effects have been reported. The advice to reduce stimulation was beneficial (effect size $0.48(0.23$ to 0.74$)$ ), whereas the advice to increase carrying and holding seemed not to reduce crying. No benefit was shown for simethicone. Uncertainty remained about the effectiveness of low lactose formula milks.

Conclusions: Infantile colic should preferably be treated by advising carers to reduce stimulation and with a one week trial of a hypoallergenic formula milk.

\section{Introduction}

Infantile colic-excessive crying in healthy, thriving infants-is a common problem during the first months of childhood. Crying typically occurs in the evenings, episodes starting in the first weeks of life and ending at the age of 4-5 months. ${ }^{1}$ In studies this crying is
Institute for Research in Extramural Medicine, Free University, Amsterdam, Netherlands P L B J Lucassen, general practitioner W J J Assendelft, general practitione J T M van Eijk, professor of general practice

Organisation for Research and Policy Advice, Grave, Netherlands

J W Gubbels, statistician

continued over

BMJ 1998;316:1563-9 